\title{
The Association of Matrix Metalloproteinase-1 Promoter Polymorphisms with Prostate Cancer in Taiwanese Patients
}

\author{
CHENG-HSI LIAO ${ }^{1,2,3}$, HSI-CHIN WU ${ }^{4}$, PEI-SHIN HU ${ }^{1,5}$, SHIH-WEI HSU ${ }^{1,2,3}$, TE-CHUN SHEN ${ }^{1,4}$, \\ TE-CHUN HSIA ${ }^{4}$, WEN-SHIN CHANG ${ }^{4}$, CHIA-WEN TSAI ${ }^{4}$ and DA-TIAN BAU ${ }^{1,4,6}$ \\ ${ }^{I}$ Graduate Institute of Biomedical Sciences, China Medical University, Taichung, Taiwan, R.O.C.; \\ ${ }^{2}$ Taichung Armed Forces General Hospital, Taichung, Taiwan, R.O.C.; \\ ${ }^{3}$ National Defense Medical Center, Taipei, Taiwan, R.O.C.; \\ ${ }^{4}$ Terry Fox Cancer Research Laboratory, Translational Medicine Research Center, \\ China Medical University Hospital, Taichung, Taiwan, R.O.C.; \\ ${ }^{5}$ Department of Ophthalmology, Changhua Christian Hospital, Changhua, Taiwan, R.O.C.; \\ ${ }^{6}$ Department of Bioinformatics and Medical Engineering, Asia University, Taichung, Taiwan, R.O.C.
}

\begin{abstract}
Background/Aim: The family of matrix metalloproteinases (MMPs) is responsible for the maintenance of extracellular matrix component homeostasis and the association of MMP-1 genetic polymorphisms with personal susceptibility to prostate cancer has only been investigated in Turkish and Japan populations and never in Taiwan. In the current study, we aimed to examine the contribution of a polymorphism in the promoter region of MMP-1 to Taiwan prostate cancer. Materials and Methods: The MMP-1 rs1799705 polymorphic genotypes were genotyped among 218 prostate cancer patients and 436 healthy controls by the typical polymerase chain reaction-restriction fragment length polymorphism (PCR-RFLP) methodology. Results: The percentages of $2 G / 2 G, 1 G / 2 G$, and $1 G / 1 G$ for MMP-1 -1607 genotypes were $36.2,40.4$ and $23.4 \%$ in the prostate cancer group and 33.7, 44.3, and $22.0 \%$ in the healthy control group ( $p$ trend=0.6362), respectively. The odds ratios (ORs) after adjusting for age and smoking status for those carrying $1 G / 2 G$ and $1 G / 1 G$ genotypes at MMP-1 -1607 were 0.84 $(95 \% C I=0.55-1.21, p=0.3862)$ and $0.94(95 \% C I=0.67-1.53$, $p=0.9586)$, respectively, compared to those carrying the wildtype $2 G / 2 G$ genotype. Supporting these findings, the adjusted OR for those carrying the $1 G$ allele at MMP-1 -1607 was 1.03 (95\%CI $=0.71-1.45, p=0.6910)$, compared to those carrying the
\end{abstract}

Correspondence to: Da-Tian Bau, Chia-Wen Tsai and Wen-Shin Chang, Terry Fox Cancer Research Laboratory, Translational Medicine Research Center, China Medical University Hospital, 2 Yuh-Der Road, Taichung, 404 Taiwan, R.O.C. Tel: +886 422053366 Ext.5805, e-mail: datian@mail.cmuh.org.tw; artbau2@gmail.com

Key Words: Genotype, $M M P-1$, polymorphism, prostate cancer, Taiwan. wild-type $2 G$ allele. Conclusion: Our findings suggest that the polymorphic genotypes at MMP-1 promoter -1607 may play a major role in determining personal cancer susceptibility for prostate cancer in Taiwan.

For many years, prostate cancer (MIM 176807) has been one of the most prevalent male cancers in western countries, such as USA, and its incidence is increasing in the Asia-Pacific countries (1). Although the rapid advances in surgical techniques and radiotherapy have improved the disease-free survival rates of prostate cancer patients with localized occurrences, the recurrence rate after radical prostatectomy, chemotherapy, or radiotherapy is still very high (2). In addition to some environmental and lifestyle-related factors, such as physical inactivity, obesity, and a high-fat diet, the most important risk factors for prostate cancer is having a family cancer history (3). Since, the prevalence rates of prostate cancer are both increasing in Taiwan and the world, to figure out feasible molecular markers for early detection and prognosis prediction of prostate cancer is one of the urgent missions for cancer genomic scientists (4).

Matrix metalloproteinases (MMPs) consist of a multigene family of zinc-dependent extracellular matrix (ECM) remodeling endopeptidases implicated in pathological processes, such as carcinogenesis $(5,6)$. In this regard, their activity plays a pivotal role in tumor growth and the multistep processes of invasion and metastasis, including proteolytic degradation of ECM, alteration of the cell-cell and cell-ECM interactions, migration and angiogenesis (7). In the literature, there are mounting few reports indicating that some $M M P$ polymorphic genotypes, especially those implicated in the expression regulation, play a critical role in determining interindividual differences of susceptibility to several types of cancer (8-16), while some others do not (17-24). 
In the literature, the most commonly investigated $M M P-1$ polymorphism is rs 1799750 at its promoter region. The $M M P-1$ rs 1799750 located at $-1,607$ of the promoter of the $M M P-1$ gene, consisting of an insertion (" $2 \mathrm{G} / 2 \mathrm{G} "$ ) polymorphism which is reported to lead to higher transcriptional activity of this gene, potentially to higher levels or rates of collagen breakdown, and higher levels of MMP-1 in their serum than those mice with $1 \mathrm{G} / 1 \mathrm{G}$ genotypes (25). A meta-analysis investigating about 10,000 cancer cases, half of which metastasized, concluded that MMP-1 rs 1799750 2G/2G genotypes had a slightly higher overall risk of metastasis (26). As for prostate cancer, the reports from Weng $\mathrm{H}$ and his colleagues investigating three studies showed that overall analyses of $M M P-1-16071 \mathrm{G} / 2 \mathrm{G}$ polymorphism and risk of prostate cancer did not reach a statistical significant level (27). However, decreased risk of prostate cancer was observed in the Caucasians for MMP-1-1607 1G/2G polymorphism (27). The authors mentioned that the decreased risk of prostate cancer concerning MMP-1-1607 1G/2G polymorphism in Caucasians might be spurious results or false positives, and the significant differences were observed based on only two studies with limited participants $(28,29)$. Since there are no previous reports investigating the contribution of $M M P-1$ rs1799750 in Taiwan, the current study aimed to examine the genetic frequencies of $M M P-1$ rs1799750 promoter genotypes and evaluating the contribution of $M M P-1$ genotypes to the susceptibility of prostate cancer in a representative Taiwanese population with 218 prostate cancer patients and 436 non-cancer healthy controls in central Taiwan.

\section{Materials and Methods}

Investigated prostate cancer and healthy control subjects. In this study, two hundred and eighteen patients diagnosed with prostate cancer were recruited at the outpatient clinics of general surgery and collected with the help of Tissuebank at the China Medical University Hospital, Taichung, Taiwan, Republic of China $(30,31)$. All patients participated voluntarily, completed a self-administered questionnaire and provided the peripheral blood samples. At the same period, a total of 436 non-prostate cancer healthy volunteers were recruited as controls, selected by matching for age, gender and habits after initial random sampling from the Health Examination Cohort of the hospital. The exclusion criteria of the control group included previous malignancy, metastasized cancer from other or unknown origin, and any familial or genetic diseases. All subjects in both groups have completed a short questionnaire which included questions about smoking and alcohol drinking habits. The study was approved by the Institutional Review Board of the China Medical University Hospital and written-informed consent was obtained from all participants.

MMP-1 genotyping methodology. The genomic DNA of the peripheral blood leukocytes of each participant was extracted, aliquoted and stored as previously described (32). The sequences of primer pairs for MMP-1 rs1799750 polymorphism were designed by our team as previously published (20). Briefly, genotyping polymerase chain reaction (PCR) cycling conditions via My Cycler (Biorad, Hercules, CA, USA) for $M M P-1$ were: one cycle at $94^{\circ} \mathrm{C}$ for $5 \mathrm{~min}$; 35 cycles of $94^{\circ} \mathrm{C}$ for $30 \mathrm{sec}, 57^{\circ} \mathrm{C}$ for $30 \mathrm{sec}$ and $72^{\circ} \mathrm{C}$ for $30 \mathrm{sec}$ and a final extension at $72^{\circ} \mathrm{C}$ for $10 \mathrm{~min}(32)$.

Statistical methodology. The deviation of the genotypic frequencies of MMP-1 polymorphisms in the healthy controls from those expected under the Hardy-Weinberg equilibrium was assessed using the goodness-of-fit test to ensure that the controls used were representative of the general population and to exclude the possibility of genotyping error. The unpaired $t$-test and Pearson's chi-square test were used to compare the ages between case and control groups, and the distribution of the $M M P-1$ genotypes between case and control groups, respectively. The associations between the $M M P-1$ polymorphisms and prostate cancer risk were estimated by computing odds ratios (ORs) and their $95 \%$ confidence intervals (CIs) from unconditional logistic regression analysis with the adjustment for possible confounders when indicated.

\section{Results}

Comparison of demographics and lifestyles between the prostate cancer patient and control groups. The distributions of frequencies of the ages and smoking status of the 218 prostate cancer patients and 436 healthy controls are summarized in Table I. Statistically, there was no difference between the two groups as for their ages $(p=0.58)$. Regarding personal smoking habits, it was found that more cancer patients $(81.2 \%)$ than healthy controls $(77.0 \%)$ were smokers $(p<0.05)$ during their life time in this selected cohort population (Table I).

Association of MMP-1 promoter genotypes and prostate cancer risk. The distributions of genetic frequencies for the investigated MMP-1 -1607 polymorphisms among the prostate cancer patients and healthy controls are presented and compared in Table II. Compared to the wild-type genotype $(2 \mathrm{G} / 2 \mathrm{G})$ sub-group, there was no significant altered risk for the hetero-variant $1 \mathrm{G} / 2 \mathrm{G}$ or homo-variant $1 \mathrm{G} / 1 \mathrm{G}$ genotypes, even after adjustment for the confounding factors including age and smoking status (adjusted $\mathrm{OR}=0.84$ and $0.94,95 \% \mathrm{CI}=0.55-1.21$ and $0.67-1.53, p=0.3862$ and 0.9586 ; respectively). The results of recessive $(2 \mathrm{G} / 2 \mathrm{G}+1 \mathrm{G} / 2 \mathrm{G}$ versus $1 \mathrm{G} / 1 \mathrm{G})$ and dominant $(2 \mathrm{G} / 2 \mathrm{G}$ versus $1 \mathrm{G} / 1 \mathrm{G}+1 \mathrm{G} / 2 \mathrm{G})$ model analysis in the carrier comparison also showed a non-significant level for the variant $1 \mathrm{G}$ allele to behave as a determinant of personal prostate cancer susceptibility in Taiwan (Table II).

Association of MMP-1 allelic subtypes and prostate cancer risk. The frequencies of the MMP-1 promoter -1607 alleles among prostate cancer patient and healthy control subjects are presented in Table III. Supporting the findings shown in Table II, the variant $1 \mathrm{G}$ allele at MMP-1 -1607 was not significantly associated with prostate cancer risk (adjusted $\mathrm{OR}=0.98,95 \% \mathrm{CI}=0.79-1.21, p=0.8439)$ (Table III). 
Table I. Demographics and life styles of the 218 prostate cancer patients and the 436 healthy control subjects in Taiwan.

\begin{tabular}{|c|c|c|c|c|c|c|c|}
\hline \multirow[t]{2}{*}{ Characteristic } & \multicolumn{3}{|c|}{ Controls $(n=436)$} & \multicolumn{3}{|c|}{ Patients $(n=218)$} & \multirow[t]{2}{*}{$p$-Value } \\
\hline & $\mathrm{n}$ & $\%$ & Mean (SD) & $\mathrm{n}$ & $\%$ & Mean (SD) & \\
\hline Age (years) & & & $63.9(6.6)$ & & & $63.6(6.9)$ & $0.58^{a}$ \\
\hline$<50$ & 275 & $63.1 \%$ & & 142 & $65.1 \%$ & & $0.67^{\mathrm{b}}$ \\
\hline$\geq 55$ & 161 & $36.9 \%$ & & 76 & $34.9 \%$ & & \\
\hline \multicolumn{8}{|l|}{ Family history } \\
\hline First degree (Father, brother, and son) & & & & 17 & $7.8 \%$ & & \\
\hline Second degree & & & & 4 & $1.8 \%$ & & \\
\hline No history & & & & 197 & $90.4 \%$ & & \\
\hline \multicolumn{8}{|l|}{ Smoking Habit } \\
\hline Ever smoker & 336 & $77.0 \%$ & & 177 & $81.2 \%$ & & $0.27^{b}$ \\
\hline Non-smoker & 100 & $23.0 \%$ & & 41 & $18.8 \%$ & & \\
\hline
\end{tabular}

aUnpaired Student's $t$-test or ${ }^{\mathrm{b}} \mathrm{Chi}$-square.

Table II. Distributions of matrix metalloproteinase-1 (MMP-1) -1607 genotypic frequencies among 218 prostate cancer cases and 436 healthy controls in Taiwan.

\begin{tabular}{lrrrr}
\hline & $\begin{array}{c}\text { Cases } \\
(\%)\end{array}$ & $\begin{array}{c}\text { Controls } \\
(\%)\end{array}$ & $\begin{array}{c}\text { Adjusted OR } \\
(95 \% \mathrm{CI})^{\mathrm{a}}\end{array}$ & $p$-Value \\
\hline MMP-1 -1607 & & & & \\
$2 \mathrm{G} / 2 \mathrm{G}$ (wild-type) & $79(36.2)$ & $147(33.7)$ & 1.00 (reference) & \\
$1 \mathrm{G} / 2 \mathrm{G}$ & $88(40.4)$ & $193(44.3)$ & $0.84(0.55-1.21)$ & 0.3862 \\
$1 \mathrm{G} / 1 \mathrm{G}$ & $51(23.4)$ & $96(22.0)$ & $0.94(0.67-1.53)$ & 0.9586 \\
$p$ for trend & & & & 0.6362 \\
Carrier comparison & & & & \\
$2 \mathrm{G} / 2 \mathrm{G}+1 \mathrm{G} / 2 \mathrm{G}$ & $167(76.6)$ & $340(78.0)$ & 1.00 (reference) & \\
$1 \mathrm{G} / 1 \mathrm{G}$ & $51(23.4)$ & $96(22.0)$ & $1.03(0.71-1.45)$ & 0.6910 \\
$2 \mathrm{G} / 2 \mathrm{G}$ & $79(36.2)$ & $147(33.7)$ & 1.00 (reference) & \\
$1 \mathrm{G} / 1 \mathrm{G}+1 \mathrm{G} / 2 \mathrm{G}$ & $139(63.8)$ & $289(66.3)$ & $0.83(0.64-1.23)$ & 0.5224 \\
\hline
\end{tabular}

OR: Odds ratio; CI: confidence interval. aData has been adjusted with confounding factors include age and smoking status; bBased on Chisquare test without Yates' correction test.

To sum up, the findings in Tables II and III are consistently supporting each other in that MMP-1 -1607 genotypic or allelic variants were not determinant factors for prostate cancer risk in Taiwan.

\section{Discussion}

A peculiarity of tumor cells is their enhanced ability to migrate and invade into adjacent tissues. The interaction of cells and extracellular matrix is dynamically regulated and plays a role in tumor migration, while the MMPs are critically responsible for maintaining the homeostasis of the components of extracellular matrix $(33,34)$. MMPs were frequently shown to be accumulated at the leading edge of
Table III. Allele frequencies of matrix metalloproteinase-1 (MMP-1) 16071 G/2G among 218 prostate cancer cases and 436 healthy controls in Taiwan.

\begin{tabular}{lcccc}
\hline Allele & $\begin{array}{c}\text { Cases (\%) } \\
\mathrm{n}=436\end{array}$ & $\begin{array}{c}\text { Controls (\%) } \\
\mathrm{n}=872\end{array}$ & $\begin{array}{c}\text { Adjusted OR } \\
(95 \% \mathrm{CI})^{\mathrm{a}}\end{array}$ & $p$-Value \\
\hline $\begin{array}{c}\text { MMP-1 -1607 } \\
\text { Allele 2G }\end{array}$ & $246(56.4)$ & $487(55.8)$ & 1.00 (reference) & 0.8439 \\
Allele 1G & $190(43.6)$ & $385(44.2)$ & $0.98(0.79-1.21)$ & \\
\hline
\end{tabular}

OR: Odds ratio; CI: confidence interval. aData has been adjusted with confounding factors include age and smoking status; bBased on Chisquare test without Yates' correction test.

elongated tumor cells during metastasis, and the upregulation of MMPs in several types of cancer from their normal conditions was often associated with poor prognosis of the cancer patients (35-39). Among breast cancer cells of different tumorigenicities, it is found that more malignant cells had increased levels of MMPs than the less malignant ones (40). Noticeably, more malignant cells do express higher levels of MMP-3, $-9,-13$, and the key player of the current study, MMP-1 (41, 42).

The investigations regarding the genotypic contribution of MMP-1 to prostate cancer are very few $(28,29)$, while there are numerous attempts to obtain molecular antagonists of integrins inhibiting signal pathways from these proteins which lead to MMP or FAK activation or stimulate vessel development in tumors (43). The promoter polymorphic site of $M M P-1,-1607$, may determine the levels of MMP-1 and influence the personal susceptibility to prostate cancer. In the current study, it was demonstrated that the genotypes of MMP-1 -1607 were non-significantly associated with prostate cancer in the investigated population in Taiwan 
(Tables II and III). This negative association is similar to those findings in Turkish and Japanese populations, respectively $(28,29)$. In 2017, Weng and his colleagues conducted a meta-analysis, and concluded that no significant association was observed between MMP-1 -1607 1G/2G polymorphism and the risk of prostate cancer (27). Although the sample size of the current study (control:case=436:218) is more representative than the previous studies in Turkish (control: case=43:55) and Japan (control: case $=251: 283$ ) populations $(28,29)$, the contribution of $M M P-1$ polymorphic genotypes to prostate cancer still needs further validation in multi-center and multi-population studies.

It is well acknowledged that prostate cancer is a multifactorial and complicated disease involving both gene and environment factors, and the contribution of smoking to prostate cancer is also of high interest. In 2010, smoking has been identified as a risk factor for prostate cancer with a meta-analysis pooling together the data from 24 individual investigations enrolling more than 26,000 participants with prostate cancer all over the world (44). We have conducted the analysis of the interaction of smoking behavior and $M M P-1-16071 \mathrm{G} / 2 \mathrm{G}$ polymorphic genotypes, finding that there is no differential distribution of the MMP-1 -1607 $1 \mathrm{G} / 2 \mathrm{G}$ polymorphic genotypes among smokers or nonsmokers (data not shown). We have to conservatively take into consideration the following two points when interpreting the results of this gene-environment interaction: a) the smoking prevalence in prostate cancer patients $(81.2 \%)$ is much higher in the cohort study than the average in Taiwan; 2) when matching the controls with the cases, the colleagues have also matched the percentages of smoking behaviors $(77.0 \%)$, therefore, the smoking percentage for the noncancer subjects is also much higher in the cohort study than the average of Taiwan.

In conclusion, our results suggest that the MMP-1 -1607 $1 \mathrm{G} / 2 \mathrm{G}$ polymorphic genotypes did not significantly predispose Taiwanese males and could not serve as good predictors for prostate cancer susceptibility. Further phenotypic studies, such as the determination of MMP-1 levels in the serum of prostate cancer patients and genotypephenotype correlations are warranted.

\section{Conflicts of Interest}

The Authors declare no conflicts of interest in regard to this study.

\section{Acknowledgements}

The Authors are grateful to Huai-Mei Hsu, Yu-Shih Wang and YunChi Wang for their excellent technical assistance. The clinical team of Dr. Wu and Chang in sample/questioneres collection and all the participants in this study are always appreciated. This study was supported partially by a research Grant from Taiwan Ministry of Health and Welfare Clinical Trial and Research Center of
Excellence (MOHW107-TDU-B-212-123004) and Taichung Armed Forces General Hospital (107A18) to Dr. Liao. The funders had no role in study design, data collection and analysis, decision to publish or preparation of the article.

\section{References}

1 Global Burden of Disease Cancer, Collaboration, Fitzmaurice C, Allen C, Barber, RM, Barregard L, Bhutta ZA et al: Global, regional, and national cancer incidence, mortality, years of life lost, years lived with disability, and disability-adjusted life-years for 32 cancer groups, 1990 to 2015: a systematic analysis for the Global Burden of Disease Study. JAMA Oncol 3: 524-548, 2017.

2 Trock BJ, Han M, Freedland SJ, Humphreys EB, DeWeese TL, Partin AW and Walsh PC: Prostate cancer-specific survival following salvage radiotherapy $v s$. observation in men with biochemical recurrence after radical prostatectomy. JAMA 299: 2760-2769, 2008.

3 Barnard RJ: Prostate cancer prevention by nutritional means to alleviate metabolic syndrome. Am J Clin Nutr 86: s889-893, 2007.

4 Chen YA, Lin YJ, Lin CL, Lin HJ, Wu HS, Hsu HY, Sun YC, Wu HY, Lai $\mathrm{CH}$ and $\mathrm{Kao} \mathrm{CH}$ : Simvastatin therapy for drug repositioning to reduce the risk of prostate cancer mortality in patients with hyperlipidemia. Front Pharmacol 9: 225, 2018.

5 Chambers AF and Matrisian LM: Changing views of the role of matrix metalloproteinases in metastasis. J Natl Cancer Inst 89 : 1260-1270, 1997.

6 Sternlicht MD and Werb Z: How matrix metalloproteinases regulate cell behavior. Annu Rev Cell Dev Biol 17: 463-516, 2001.

7 Gialeli C, Theocharis AD and Karamanos NK: Roles of matrix metalloproteinases in cancer progression and their pharmacological targeting. FEBS J 278: 16-27, 2011.

8 Tsai CW, Chang WS, Gong CL, Shih LC, Chen LY, Lin EY, Li HT, Yen ST, Wu CN and Bau DT: Contribution of matrix metallopeptidase-1 genotypes, smoking, alcohol drinking and areca chewing to nasopharyngeal carcinoma susceptibility. Anticancer Res 36: 3335-3340, 2016.

9 Sun KT, Tsai CW, Chang WS, Shih LC, Chen LY, Tsai MH, Ji HX, Hsiao CL, Liu YC, Li CY and Bau DT: The contribution of matrix metalloproteinase-1 genotype to oral cancer susceptibility in Taiwan. In Vivo 30: 439-444, 2016.

10 Ye S: Polymorphism in matrix metalloproteinase gene promoters: implication in regulation of gene expression and susceptibility of various diseases. Matrix Biol 19: 623-629, 2000.

11 Price SJ, Greaves DR and Watkins H: Identification of novel, functional genetic variants in the human matrix metalloproteinase-2 gene: role of $\mathrm{Sp} 1$ in allele-specific transcriptional regulation. J Biol Chem 276: 7549-7558, 2001.

12 Yu C, Zhou Y, Miao X, Xiong P, Tan W and Lin D: Functional haplotypes in the promoter of matrix metalloproteinase-2 predict risk of the occurrence and metastasis of esophageal cancer. Cancer Res 64: 7622-7628, 2004.

13 Elander N, Soderkvist P and Fransen K: Matrix metalloproteinase (MMP) $-1,-2,-3$ and -9 promoter polymorphisms in colorectal cancer. Anticancer Res 26: 791-795, 2006.

14 Li Y, Jin X, Kang S, Wang Y, Du H, Zhang J, Guo W, Wang N and Fang S: Polymorphisms in the promoter regions of the matrix metalloproteinases-1, $-3,-7$, and -9 and the risk of epithelial ovarian cancer in China. Gynecol Oncol 101: 92-96, 2006. 
15 Hu Z, Huo X, Lu D, Qian J, Zhou J, Chen Y, Xu L, Ma H, Zhu J, Wei $Q$ and Shen H: Functional polymorphisms of matrix metalloproteinase- 9 are associated with risk of occurrence and metastasis of lung cancer. Clin Cancer Res 11: 5433-5439, 2005.

16 Chou AK, Hsiao CL, Shih TC, Wang HC, Tsai CW, Chang WS, Liu LC, Way TD, Chung JG and Bau DT: The contribution of matrix metalloproteinase-7 promoter genotypes in breast cancer in Taiwan. Anticancer Res 37: 4973-4977, 2017.

17 Hsiao CL, Liu LC, Shih TC, Chuang CL, Chen GL, Wang HC, Pan SY, Shen TC, Tsai CW, Chang WS, Way TD, Chung JG and Bau DT: The association of matrix metalloproteinase- 8 promoter genotypes in breast cancer. Anticancer Res 38: 21812185, 2018.

18 Shih LC, Li CH, Sun KT, Chen LY, Hsu CL, Hung YW, Wu CN, Hsia TC, Shen TC, Chang WS, Shih TC, Tsai CW and Bau DT: Association of matrix metalloproteinase-7 genotypes to the risk of oral cancer in Taiwan. Anticancer Res 38: 2087-2092, 2018.

19 Hung YW, Tsai CW, Wu CN, Shih LC, Chen YY, Liu YF, Hung HS, Shen MY, Chang WS and Bau DT: The contribution of matrix metalloproteinase- 8 promoter polymorphism to oral cancer susceptibility. In Vivo 31: 585-590, 2017.

20 Liao CH, Chang WS, Hu PS, Wu HC, Hsu SW, Liu YF, Liu SP, Hung HS, Bau DT and Tsai CW: The contribution of MMP-7 promoter polymorphisms in renal cell carcinoma. In Vivo 31: 631-635, 2017.

21 Shen TC, Hsia TC, Chao CY, Chen WC, Chen CY, Chen WC, Lin YT, Hsiao CL, Chang WS, Tsai CW and Bau DT: The contribution of MMP-8 promoter polymorphisms in lung cancer. Anticancer Res 37: 3563-3567, 2017.

$22 \mathrm{Hu}$ PS, Chang WS, Chou AK, Hsia NY, Hung YW, Lin CW, Wu CW, Huang CY, Wu MF, Liao CH, Tsai CW, Bau DT and Gong CL: The association of MMP-8 genotypes with pterygium. In Vivo 32: 41-46, 2018.

23 Pei JS, Chang WS, Hsu PC, Hung YW, Cheng SP, Tsai CW, Bau DT and Gong CL: The contribution of MMP-8 promoter genotypes to childhood leukemia. In Vivo 31: 1059-1064, 2017.

24 Przybylowska K, Kluczna A, Zadrozny M, Krawczyk T, Kulig A, Rykala J, Kolacinska A, Morawiec Z, Drzewoski J and Blasiak J: Polymorphisms of the promoter regions of matrix metalloproteinases genes MMP-1 and MMP-9 in breast cancer. Breast Cancer Res Treat 95: 65-72, 2006.

25 Tower GB, Coon CI and Brinckerhoff CE: The 2G single nucleotide polymorphism (SNP) in the MMP-1 promoter contributes to high levels of MMP-1 transcription in MCF-7/ADR breast cancer cells. Breast Cancer Res Treat 82: 75-82, 2003.

26 Liu D, Guo H, Li Y, Xu X, Yang K and Bai Y: Association between polymorphisms in the promoter regions of matrix metalloproteinases (MMPs) and risk of cancer metastasis: a meta-analysis. PLoS One 7: e31251, 2012.

27 Weng H, Zeng XT, Wang XH, Liu TZ and He DL: Genetic association between matrix metalloproteinases gene polymorphisms and risk of prostate cancer: A Meta-Analysis. Front Physiol 8: 975, 2017.

28 Albayrak S, Canguven O, Goktas C, Aydemir H and Koksal V: Role of MMP-1 $1 \mathrm{G} / 2 \mathrm{G}$ promoter gene polymorphism on the development of prostate cancer in the Turkish population. Urol Int 79: 312-315, 2007.

29 Tsuchiya N, Narita S, Kumazawa T, Inoue T, Ma Z, Tsuruta H, Saito M, Horikawa Y, Yuasa T, Satoh S, Ogawa O and Habuchi $\mathrm{T}$ : Clinical significance of a single nucleotide polymorphism and allelic imbalance of matrix metalloproteinase-1 promoter region in prostate cancer. Oncol Rep 22: 493-499, 2009.

$30 \mathrm{Wu} \mathrm{HC}$, Chang $\mathrm{CH}$, Ke HL, Chang WS, Cheng HN, Lin HH, Wu CY, Tsai CW, Tsai RY, Lo WC and Bau DT: Association of cyclooxygenase 2 polymorphic genotypes with prostate cancer in taiwan. Anticancer Res 31: 221-225, 2011.

$31 \mathrm{Wu} \mathrm{HC}$, Chang CH, Tsou YA, Tsai CW, Lin CC and Bau DT: Significant association of caveolin-1 (CAV1) genotypes with prostate cancer susceptibility in Taiwan. Anticancer Res 31: 745$749,2011$.

32 Lai YL, Gong CL, Fu CK, Yueh TC, Tsai CW, Chang WS, Hsiao CL, Yen ST, Li HT, Jeng LB, Wang SC and Bau DT: The contribution of matrix metalloproteinase-1 genotypes to hepatocellular carcinoma susceptibility in Taiwan. Cancer Genomics Proteomics 14: 119-125, 2017.

33 Egeblad $M$ and Werb Z: New functions for the matrix metalloproteinases in cancer progression. Nat Rev Cancer 2: 161-174, 2002.

34 Deryugina EI and Quigley JP: Matrix metalloproteinases and tumor metastasis. Cancer Metastasis Rev 25: 9-34, 2006.

35 Forget MA, Desrosiers RR and Beliveau R: Physiological roles of matrix metalloproteinases: Implications for tumor growth and metastasis. Can J Physiol Pharmacol 77: 465-480, 1999.

36 Nikkola J, Vihinen P, Vuoristo MS, Kellokumpu-Lehtinen P, Kahari VM and Pyrhonen S: High serum levels of matrix metalloproteinase-9 and matrix metalloproteinase-1 are associated with rapid progression in patients with metastatic melanoma. Clin Cancer Res 11: 5158-5166, 2005.

37 Yasui W, Oue N, Aung PP, Matsumura S, Shutoh M and Nakayama H: Molecular-pathological prognostic factors of gastric cancer: A review. Gastric Cancer 8: 86-94, 2005.

38 Curran S, Dundas SR, Buxton J, Leeman MF, Ramsay R and Murray GI: Matrix metalloproteinase/tissue inhibitors of matrix metalloproteinase phenotype identifies poor prognosis colorectal cancers. Clin Cancer Res 10: 8229-8234, 2004.

39 Bostrom P, Soderstrom M, Vahlberg T, Soderstrom KO, Roberts PJ, Carpen O and Hirsimaki P: MMP-1 expression has an independent prognostic value in breast cancer. BMC Cancer 11: 348, 2011.

40 Wang C, Hu F, Guo S, Mi D, Shen W, Zhang J, Qiao Y, Zhu T and Yang S: BMP-6 inhibits MMP-9 expression by regulating heme oxygenase-1 in MCF-7 breast cancer cells. J Cancer Res Clin Oncol 137: 985-995, 2011.

41 Bachmeier BE, Nerlich AG, Lichtinghagen R and Sommerhoff CP: Matrix metalloproteinases (MMPs) in breast cancer cell lines of different tumorigenicity. Anticancer Res 21: 3821-3828, 2001.

42 Benaud C, Dickson RB and Thompson EW: Roles of the matrix metalloproteinases in mammary gland development and cancer. Breast Cancer Res Treat 50: 97-116, 1998.

43 Moschos SJ, Drogowski LM, Reppert SL and Kirkwood JM: Integrins and cancer. Oncology (Williston Park) 21: 13-20, 2007.

44 Huncharek M, Haddock KS, Reid R and Kupelnick B: Smoking as a risk factor for prostate cancer: A meta-analysis of 24 prospective cohort studies. Am J Public Health 100: 693-701, 2010.

Received April 25, 2018

Revised May 18, 2018

Accepted May 22, 2018 